\title{
Perancangan Helpdesk Sistem Model Berbasis Itil Versi 3 Domain Problem Management Dan Incident Management
}

\author{
Ali Imron ${ }^{1)}$, Widya Cholil ${ }^{2)}$, Linda Atika ${ }^{3)}$ \\ ${ }^{12) 3)}$ Program Pascasaarjana Magister Teknik Informatika, Universitas Bina Darma Palembang \\ Jl. Jenderal Ahmad Yani No.3, 9/10 Ulu, Kota Palembang, Sumatera Selatan 30111 \\ Email : imron111992@ gmail.com ${ }^{1)}$, widya.cholil@binadarma.ac.id ${ }^{2}$, linda.atika@binadarma.ac.id ${ }^{3)}$
}

\begin{abstract}
The management of information technology service management at this time is very influential for the organization in achieving its strategic objectives. A large ITIL collection of best practices, tools and methods used in the management and handling of IT services. In this paper, the emphasis will be placed on the Operations Services field at ITIL on the incident management process used to manage the IT incident life cycle. The main idea is to find solutions for optimal planning of interventions that are automated in the incident management process. Indeed, despite the number of software solutions for the incident management process, intervention planning is still the user's task due to the high complexity of its automation. In this paper, we propose two solutions for optimal automated planning of interventions in incident management. The first is inspired by vehicle routing problems and the second is inspired by obstacle-based problems. Finally, we will compare the results of the two solutions. This research will analyze and design the service problems that occur in seconds by using the domain problem management and incident management contained in the service operation which is a sub domain of ITIL. ITIL in the concept of research data collection using interviews and literature studies, in which the data generated from this method there are several incidents that often occur in seconds, so that will be presented a result. System helpdesk that will provide a conclusion of several incidents that often occur and are complained of by system users. From the results of the incident that occurred, it will be carried out according to the flow of the helpdesk that has been built and if an incident occurs repeatedly, it will become a management problem.
\end{abstract}

Keywords : ITIL, IT design, problem management, incident management, and service operation

\begin{abstract}
Abstrak
Pengendalian manajemen pelayanan teknologi informasi pada saat ini sangat berpengaruh untuk organisasi dalam mencapai tujuan strateginya. Sekumpulan ITIL besar praktik, alat, dan metode terbaik yang digunakan dalam pengelolaan dan penanganan layanan TI. Dalam tulisan ini, akan menempatkan penekanan pada field Layanan Operasi di ITIL pada proses manajemen insiden yang digunakan untuk mengelola siklus hidup insiden TI. Gagasan utamanya adalah menemukan solusi untuk perencanaan optimal intervensi yang otomatis dalam proses manajemen insiden. Memang, meskipun jumlah solusi perangkat lunak untuk proses manajemen insiden, perencanaan intervensi masih merupakan tugas pengguna karena kompleksitas tinggi otomatisasi nya. Dalam tulisan ini, kami mengusulkan dua solusi untuk perencanaan optimal otomatis intervensi dalam pengelolaan insiden. Yang pertama terinspirasi oleh masalah perutean kendaraan dan yang kedua terinspirasi oleh masalah berbasis kendala. Akhirnya, kita akan membandingkan antara hasil dua solusi tersebut.Penelitian ini akan menganalisa dan melakukan desain perancangan terhadap masalah pelayanan yang terjadi pada detik sumsel dengan menggunakan domain problem management dan incident management yang terdapat pada service operation yang merupakan sub domain dari ITIL. ITIL dalam konsep penelitian pengumpulan data menggunakan metode wawancara dan studi literatur, yang mana data yang dihasilkan dari metode ini terdapat beberapa insiden yang sering terjadi pada detik sumsel, sehingga akan disajikan sebuah hasil. Helpdesk sistem yang akan memberikan sebuah kesimpulan dari beberapa insiden yang sering terjadi dan dikeluhkan oleh pengguna sistem. Dari hasil insiden yang terjadi maka akan dilakukan sebuah penanganan sesuai alur dari helpdesk yang telah dibangun dan jika sebuah insiden terjadi berulang kali maka semua itu akan dijadikan sebuah problem management.
\end{abstract}

Kata kunci : ITIL, desain TI, problem management, incident managemant, dan service operation 


\section{Pendahuluan}

Manajemen pelayanan adalah kemampuan organisasi khusus untuk memberikan hasil kepada pelanggan dalam bentuk layanan. "Kemampuan Khusus Organisasi" meliputi proses, kegiatan, fungsi dan peran yang menggunakan penyedia layanan dalam memberikan layanan kepada pelanggan mereka, serta kemampuan untuk membangun struktur organisasi yang sesuai, mengelola pengetahuan dan memahami bagaimana memberikan hasil yang menciptakan penilaian. profesi diterima secara luas bahwa kata profesi berlaku di mana sekelompok orang berbagi standar umum dan disiplin berdasarkan tingkat tinggi pengetahuan dan keterampilan, yang diperoleh dari skema pendidikan terorganisir didukung oleh pelatihan melalui pengalaman dan diukur dan diakui melalui kualifikasi formal.

Selain itu, profesi berusaha untuk memberikan pengaruhnya melalui pengembangan pedoman praktik yang baik dan saran untuk meningkatkan standar kinerja di bidang tertentu. kerangka kerja untuk menyusun kegiatan dan interaksi yang terkait dengan TI antara tenaga teknis TI dan pengguna teknologi informasi. ITSM umumnya menangani masalah operasional manajemen teknologi informasi (kadang disebut operations architecture, arsitektur operasi) dan bukan pengembangan teknologi itu sendiri. Sebagai contoh, proses pembuatan perangkat lunak komputer untuk dijual bukan fokus dari disiplin saja, tetapi sistem komputer yang digunakan oleh pemasaran dan pengembangan bisnis di perusahaan-perusahaan perangkat lunak itu sendir harus fokus dan memberikan perhatian. Banyak perusahaan non-teknologi, seperti di industri keuangan, ritel dan pariwisata, memiliki sistem IT yang memainkan peran penting, meskipun mereka tidak secara langsung terekspos kepada konsumen.

Layanan TI yang ada pada saat ini salah satunya ialah Detik sumsel. Dimana, detik sumsel pada bagian operasionalnya telah memanfaatkan teknologi informasi untuk mendukung proses bisnisnya. Hingga saat ini kegiatan operasional detik sumsel dinilai sudah cukup baik dalam memberikan layanan TI. Akan tetapi belum diketahui sejauh mana layanan teknologi informasi yang telah digunakan mampu bekerja secara efektif dan efisien dalam mencapai target organisasi.

Terdapat banyak standar kerangka kerja pengelolaan TI dari berbagai aspek tinjauan. Manajemen layanan merupakan salah satu standar kerangka kerja pengelolaan TI. Standar kerangka kerja tata kelola TI yang dikenal diantaranya adalah Infrastructure Technology Information Library (ITIL), ISO/IEC 20000, COBIT dan ISO /IEC 38500. Dari standar kerangka kerja tata kelola TI yang disebutkan, yang termasuk kepada bagian manajemen layanan TI ialah ITIL dan ISO 20000. ITIL sebuah layanan TI dari ide pengadaan, perencanaan, pengembangan sistem, operasional layanan TI, dan perbaikan serta pengembangan, hingga layanan TI dihentikan. ITIL memiliki beberapa siklus hidup sebuah layanan TI yang direkomendasikan (Susanto, 2016:37). ITIL version 3 memiliki beberapa domain yaitu Service Strategy, Service Design, Service Transition, Service Operation dan Continual Service Improvement.

Penelitian ini menggunakan rangkaian yang ada pada ITIL yaitu service operation, dengan menggunakan domain problem managemant dan incident management yang dimiliki oleh detik sumsel. Hasil penelitianya memberikan gambaran dokumentasi untuk meningkatkan layanan pada bagian problem management dan incident management.

\section{A. Kajian Pustaka}

1. IT Service Management (ITSM)

ITSM adalah suatu IT Service Management yang memiliki kemampuan untuk memberikan nilai kepada pelanggan dalam bentuk layanan dan kemampuan itu bertujuan untuk lebih meningkatkan efektifitas dan efisiensi dalam pemberian layanan kepada pelanggan. Manfaat dari IT service management adalah:

a. Peningkatan mutu penyediaan layanan

b. Biaya kualitas pelayanan sesuai dengan kualitas layanan

c. Pelayanan yang memenuhi bisnis, pelanggan dan tuntutan dari user

d. Proses Bisnis yang terjadi dapat lebih terpusat

e. Setiap orang mengetahui peran dan tanggung jawab mereka dalam penyediaan layanan

f. Belajar dari pengalaman sebelumnya

g. Indikator kinerja dapat dibuktikan

Perspektif untuk menjelaskan konsep IT service management yaitu :

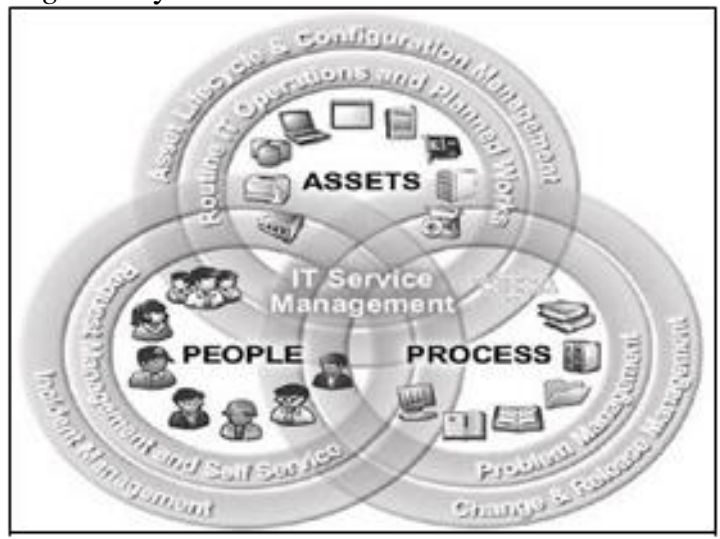

Gambar 1. Perspektif IT Service Management

\section{Framework ITIL}

Information Technology Infrastructure library (ITIL) adalah sebuah konsep dan praktik untuk mengelola layanan TI, pengembangan dan pengoperasian TI. ITIL memberikan uraian terperinci tentang sejumlah praktik TI penting dan memberikan daftar tugas dan prosedur yang komprehensif di mana setiap organisasi dapat beradaptasi dengan kebutuhannya sendiri. Siklus layanan ITIL meningkatkan kemampuan semua proses dan alat ITSM. 


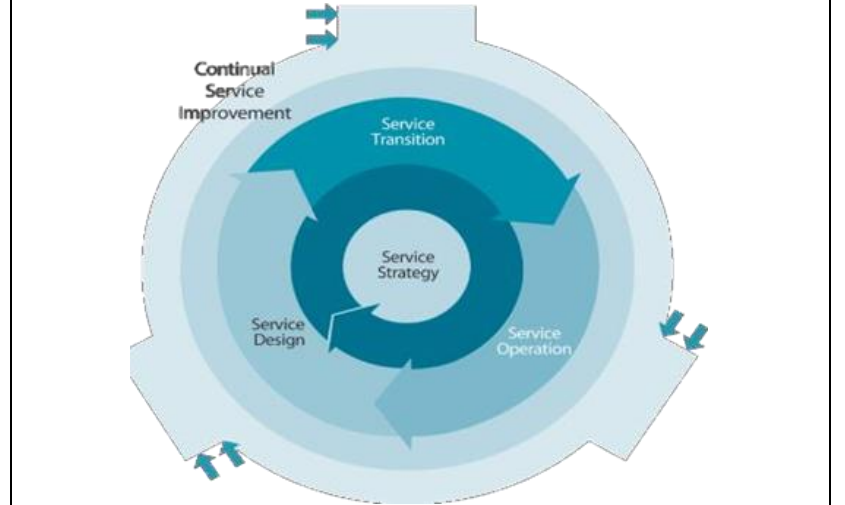

Gambar 2. Siklus layanan ITIL V3 (Maita indria dan Akmal sapri:2016)

Terdapat beberapa framework yang dapat digunakan sebagai acuan dalam penerapan tata kelola TI di perusahaan, seperti Information Technology Infrastructure Library (ITIL), Control Objectives for Information and Related Technology (COBIT), ISO/EIC 20000, dan Enchanced Telecom Operation Map (eTOM). Framwork tersebut berfungsi untuk membantu dalam meningkatkan efisien dan efektivitas dalam proses bisnis suatu perusahaan dengan hasil yang berupa temuan-temuan

\section{Service operation}

Menurut meita indria dan akmal sapri (2016) Service Operation merupakan tahapan lifecycle yang mencakup semua kegiatan operasional harian pengelolaan layananlayanan TI. Di dalamnya terdapat berbagai panduan pada bagaimana mengelola layanan TI secara efisien dan efektif serta menjamin tingkat kinerja yang telah diperjanjikan dengan pelanggan sebelumnya. Proses yang ada pada Sevice Operation :
a. Event Management
b. Request Fulfilment
c. Acces Management
d. Problem Management
e. Incident Management

Tujuan dari Operasi Layanan adalah untuk memberikan tingkat layanan yang disepakati kepada pengguna dan pelanggan,dan untuk mengelola aplikasi, teknologi dan infrastruktur yang mendukung pemberian layanan.

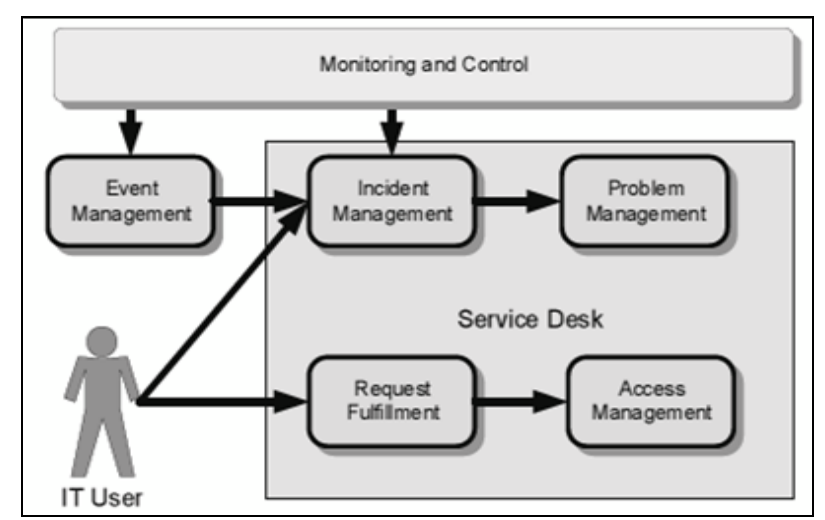

Gambar 3. Diagram proses dan kegiatan dari Service Operation (susilowati:2012)

\section{Incident management}

Menurut susilowati (2012), Incident Management adalah proses menangani semua insiden, termasuk kegagalan, dengan staf teknikal atau secara otomatis dideteksi dan dilaporkan tool monitoring event. Tujuannya adalah untuk mengembalikan kegiatan layanan yang normal secepat mungkin dan meminimalisasikan pengaruh pada kegiatan bisnis sekaligus memastikan bahwa tahapan yang paling baik dari kualitas layanan dan ketersediaannya telah diatur. Perbedaan antara Incident Management dan Problem Management adalah dari cara penyelesaiannya. Incident Management akan menyelesaikan masalah apabila terjadi masalah. Sedangkan Problem Management akan menyelesaikan sebelum masalah terjadi, dan hal tersebut dilakukan secara permanen.

\section{Problem Management}

Problem Management merupakan analisis yang dilakukan untuk mengetahui penyebab utama dan menyelesaikan penyebab dari insiden secara permanen, kegiatan Problem Management dilakukan secara proaktif. Tujuan dari Problem Management adalah untuk meminimalkan akibat negatif dari sebuah insiden yang disebabkan adanya kerusakan infrastruktur IT, dan juga untuk menghindari terjadinya insiden.

\section{B. Metodelogi Penelitian}

Penelitian ini menggunakan tiga tahapan yaitu sebagai berikut:

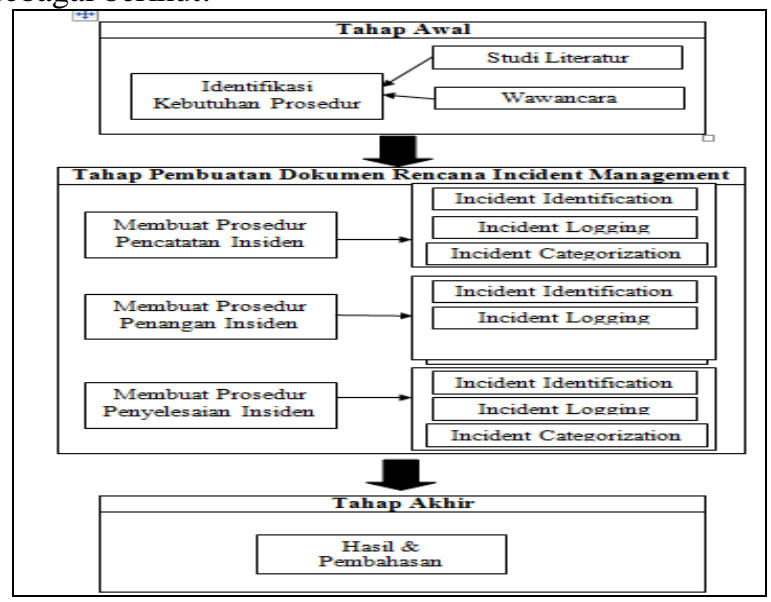

Gambar 4. Tahapan penelitian

1. Tahapan Awal

Tahap awal yang dilakukan oleh peneliti dalam mempersiapkan pelaksanaan pengerjaan tugas akhir. Pada tahap awal ini terdapat dua tahapan yaitu studi literatur serta wawancara. Studi literatur digunakan untuk memperoleh data dan pengetahuan yang mendukung penelitian tugas akhir. Wawancara digunakan untuk mengumpulkan data-data pendukung dalam mengidentifikasi dan menganalisa permasalahan. Observasi yang dilakukan bertujuan untuk mengamati proses dan kegiatan penanganan insiden pada perusahaan.

\section{Studi Literatur}

Studi literatur penelitian dilakukan pada saat pengerjaan penelitian. literatur dilakukan dengan cara 
mempelajari dan mencari referensi, yang mendasar keterkaitan topik penelitian. Pencarian referensi yang berkaitan dengan topik penelitian melalui buku dan informasi via web. Hal ini bertujuan untuk memperoleh data dan pengetahuan yang lebih mengenai perencanaan Incident Management dan problem management yang akan dibuat.

\section{Wawancara}

Wawancara yang dilakukan pada penelitian ini dilakukan selama beberapa hari. Pada langkah ini bertujuan untuk menemukan permasalahan yang ada atau peluang yang bisa diberikan sebagai rekomendasi untuk meningkatkan proses saat ini. Kegiatan wawancara ini dilakukan secara langsung dan melakukan tanya jawab pada pegawai detik sumsel. Pegawai yang diwawancarai yaitu bagian IT support.

Berdasarkan framework ITIL v3 peran yang berkaitan dengan mendukung jalannya service operation adalah service owner, process owner dan process manager. Service owner sebagai pemilik layanan atau penanggung jawab atas layanan IT tertentu. Process owner memiliki tanggung jawab untuk memastikan suatu proses telah sesuai dengan tujuan, sedangkan process manager memiliki tanggung jawab terkait kegiatan manajemen operasional suatu proses. ITIL mendefinisikan fungsi merupakan sebuah tim atau regu yang bertanggung jawab menangani suatu proses. Service Desk disini bertanggung jawab terkait dalam menangani proses incident management. Assistant Manager App memiliki peran dan tanggung jawab untuk mengelola dan menyediakan perangkat lunak.

\section{Pembahasan}

A. Analisis Tahapan Pada Incident Management

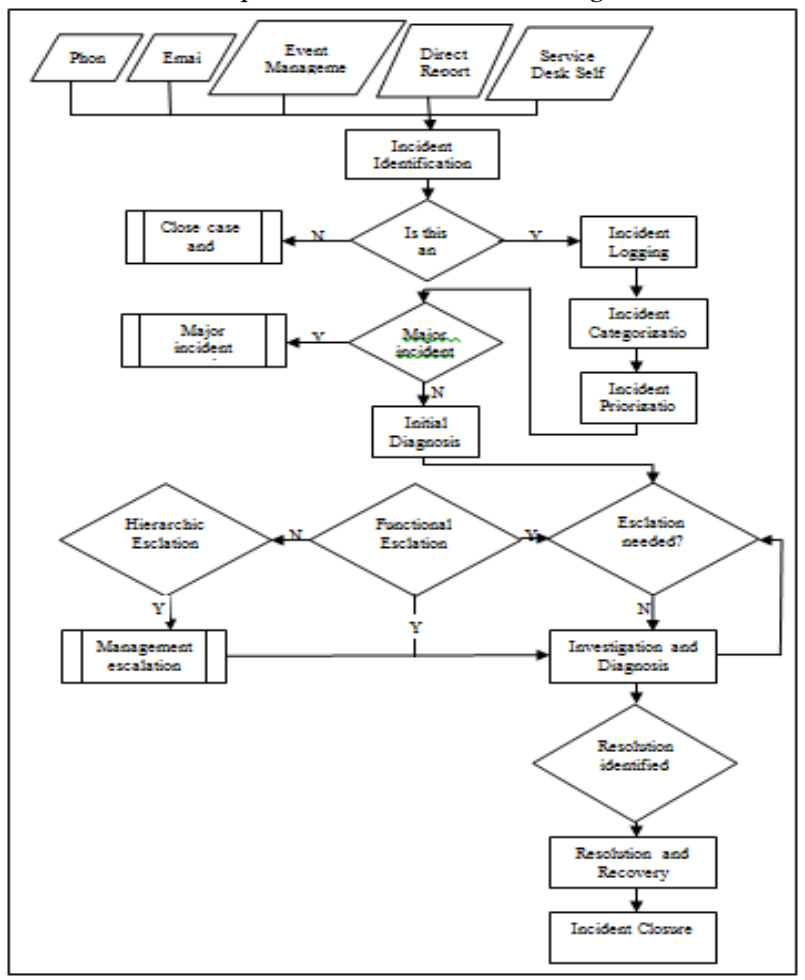

Gambar 5. Proses Incident Management
Tahapan yang terdapat pada incident management:

1. Identifikasi insedent

Identifikasi gangguan dilakukan dari laporan yang diterima dari IT suport, tahapan ini melalui:

a. Laporan dari user kepada service desk baik secara langsung atau via telepon.

b. Dilaporkan melalui email.

c. Dilaporkan secara langsung kepada stap IT support.

Sehingga pada tahapan ini didapatlah beberapa insiden yang terjadi pada detik sumsel yaitu sebagai berikut:

Tabel 1. Insiden yang terjadi pada detik sumsel

\begin{tabular}{|c|c|c|}
\hline No & $\begin{array}{c}\text { Jenis } \\
\text { Layanan }\end{array}$ & Insiden \\
\hline 1 & $\begin{array}{c}\text { Layanan } \\
\text { iklan }\end{array}$ & $\begin{array}{l}\text { 1. Iklan tidak sempurna } \\
\text { tampil } \\
\text { 2. Waktu tayang iklan yang } \\
\text { tidak bisa dipastikan } \\
\text { 3. Konfirmasi masalah yang } \\
\text { lambat karena sering } \\
\text { terjadi pemesanan secara } \\
\text { bersamaan karena tidak } \\
\text { ada hepdest dan CS } \\
\text { 4. Proses pembayaran yang } \\
\text { rumit }\end{array}$ \\
\hline 2 & $\begin{array}{c}\text { Layanan } \\
\text { Berita }\end{array}$ & $\begin{array}{l}\text { 1. Jangka waktu tayang } \\
\text { berita yang terlalu lama } \\
\text { karena melalui tahapan } \\
\text { sebelum tayang } \\
\text { 2. Tayang berita serng terjadi } \\
\text { kesalahan karena berita } \\
\text { dikirim oleh masing2 } \\
\text { wartawan tanpa dicek } \\
\text { pihak redaksi terlebih } \\
\text { dahulu } \\
\text { 3. Masalah jaringan pada saat } \\
\text { upload berita karena } \\
\text { banyak wartawan yang } \\
\text { bertugas didaerah yang } \\
\text { minim jaringan internet. }\end{array}$ \\
\hline
\end{tabular}

2. Pencatatan insident

Semua insiden yang dilaporkan client dicatat sepenuhnya tanggal dan waktunya. Semua kejadian dan tindakan yang dilakukan dalam penanganan insiden harus dicatat sehingga semua histori dapat dirawat dan dijadikan informasi dalam penanganan insiden selanjutnya oleh IT suport

Informasi yang perlu dicatat dalam insiden adalah sebagai berikut:
a. Urgensi insiden
b. Dampak insiden
c. Prioritas insiden 
Tabel 2. Penilaian Tingkat Gangguan

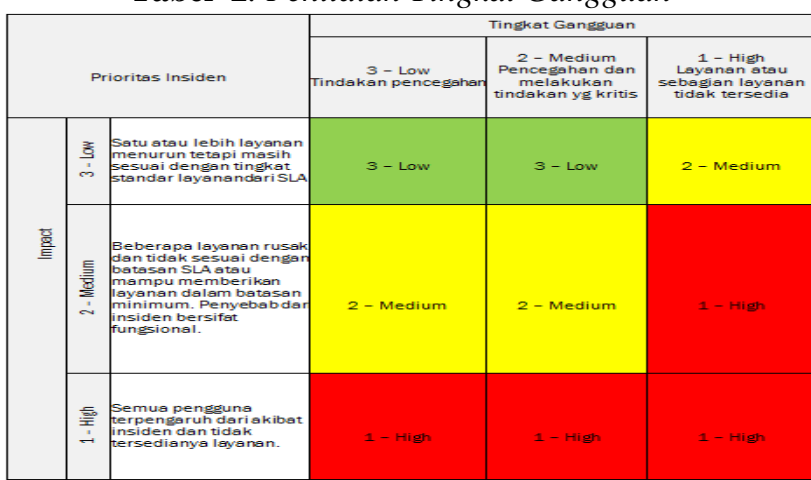

\section{Pengkatagorian insiden}

Proses khusus untuk mengkategorisasikan sebuah insiden yang sesuai dengan kejadian, sehingga jenis kejadian dapat dicatat dengan tepat. Hal ini berujuan untuk menghasilakan katagori insiden yang digunakan dalam menemukan frekuensi insiden karena sifat dan bentuk organisasi yang beragam. Katagori insiden dapat ditentukan melalui jangka waktu penanganan, dampak yang diberikan. Langkah-langkah yang dapat dilakukan dalam melakukan pengkatagorian insiden adalah:

a. Melakukan diskusi dan pembahasan dengan pihakpihak terkait melibatkan supervisor, service desk, bagian penanganan insiden atau problem dan manajer.

b. Menentukan poin kategori top level hingga ke low level insiden, sesuai dengan kebutuhan pelanggan.

c. Menggunakan kategori insiden yang telah ditentukan dalam jangka waktu yang singkat terlebih dahulu.

Tabel 3. Target Waktu Penanganan Gangguan

\begin{tabular}{|c|c|c|}
\hline \multirow{2}{*}{ Prioritas } & \multicolumn{2}{|c|}{ Target } \\
\cline { 2 - 3 } & Respon & Resolves \\
\hline 3 - Low & $90 \%-24$ hours & $90 \%-7$ days \\
\hline 2 - Medium & $90 \%-2$ hours & $90 \%-4$ hours \\
\hline 1 - High & $95 \%-15$ minutes & $90 \%-2$ hours \\
\hline
\end{tabular}

\section{Pemrioritasan Insiden}

Pemrioritasan insiden merupakan aspek penting yang perlu dilakukan oleh perusahaan untuk menentukan bagaimana kejadian ditangani dengan baik oleh alat pendukung maupun staf tenaga ahli. Pemrioritasan dapat ditentukan dengan cara memperhitungkan urgensi dari suatu insiden atau kejadian melihat dari tingkat dampak yang diberikan terhadap bisnis. Faktorfaktor berpengaruh dalam menentukan tingkat dampak yang diberikan adalah seb berikut:

a. Resiko terhadap keberlangsungan hidup perusahaan.

b. Jumlah layanan yang terkena dampak dari insiden.

c. Dampak terhadap reputasi bisnis.
Tabel 4. Hubungan Penanganan Insident

\begin{tabular}{|c|c|c|c|c|c|c|}
\hline \multirow[b]{2}{*}{ No } & \multirow[b]{2}{*}{ Incident } & \multicolumn{3}{|c|}{ Tingkat Gangguan } & \multicolumn{2}{|c|}{ Target } \\
\hline & & 3 - Low & 2 - Medium & $\begin{array}{l}1- \\
\text { High }\end{array}$ & Respon & Resolves \\
\hline 1 & $\begin{array}{l}\text { Waktu tampil yang } \\
\text { iklan yang tidak bisa } \\
\text { dipastikan }\end{array}$ & & $\mathrm{x}$ & & 2 hours & 3 hours \\
\hline 2 & $\begin{array}{l}\text { Konfirmasi lambat } \\
\text { karena sering terjadi } \\
\text { pemesanan secara } \\
\text { bersamaan }\end{array}$ & & $X$ & & 2 hours & 3 hours \\
\hline 3 & $\begin{array}{l}\text { Proses pembayaran } \\
\text { yang rumit }\end{array}$ & & $\mathrm{X}$ & & 2 hours & 3 hours \\
\hline 4 & $\begin{array}{l}\text { Jangka waktu berita } \\
\text { terlalu lama }\end{array}$ & & $\mathrm{x}$ & & 2 hours & 3 hours \\
\hline 5 & Kesalahan berita & & & $\mathrm{X}$ & $\begin{array}{c}15 \\
\text { minutes }\end{array}$ & 1 hours \\
\hline 6 & Jaringan lambat & & $x$ & & 2 hours & 3 hours \\
\hline 7 & $\begin{array}{l}\text { Iklan tidak sempurna } \\
\text { tampil }\end{array}$ & $\mathrm{X}$ & & & 24 hours & 4 hours \\
\hline
\end{tabular}

5. Diagnosis Inisiasi

Insiden yang dilaporkan melalui service desk dapat dilakukan diagnosa awal. Pada saat user melakukan panggilan telepon bagian staf service desk diharapkan dapat menagani insiden yang disampaikan user pada saat melakukan panggilan. Diagnosis awal insiden dilakukan berdasarkan hasil dari analisis informasi yang diberikan oleh user. Apabila staf service desk masih belum mampu membantu menyelesaikan permasalahan secara langsung, maka service desk meminta waktu untuk mencatat insiden tersebut dan memberi nomer referensi pengaduan agar dapat diselesaikan bagian atau unit yang kompeten dalam menangani hal tersebut.

6. Penanganan Insiden

Proses tindakan menaikan level penanganan insiden hasil dari temuan diagnosa penanganan insiden yang tidak dapat ditangani dalam jangka waktu tertentu, maka harus melakukan pengukuran terhadap insiden. Sehingga guna memberikan sebuah penenganan insiden maka akan dibuat sebuah alur yang dapat membantu dalam proses penanganan insiden yaitu dengan DFD, ERD, dan Flowchart.

a. Flowchart

Setelah dilakukan analisis kebutuhan sistem, maka peneliti akan membuat flowchart helpdesk system, untuk mengetahui alur dari sistem yang dibuat. Adapun gambar flowchart dapat dilihat pada Gambar 4.2 sebagai berikut:

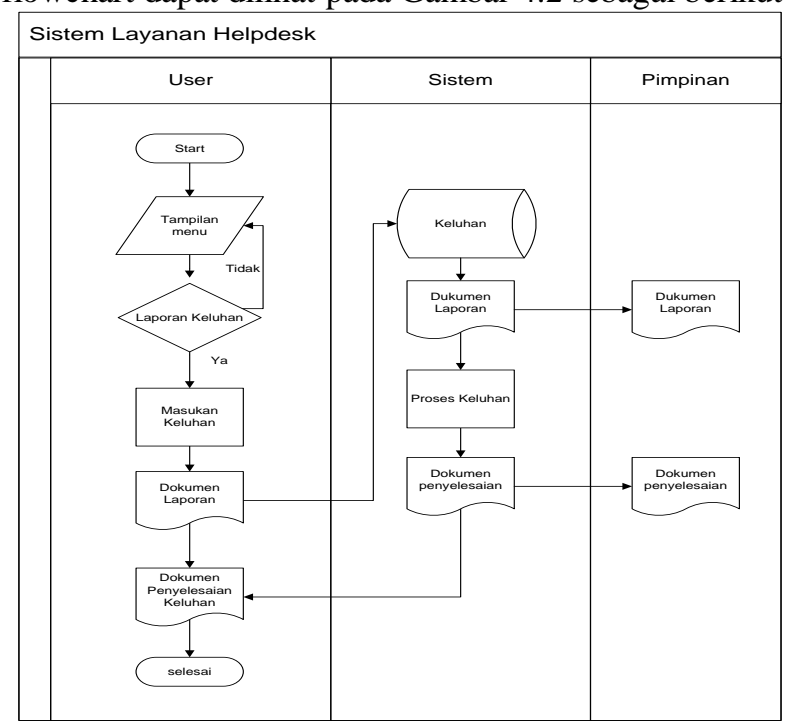

Gambar 6. Flowchart Helpdesk System 
b. Diagram Konteks

Setelah dilakukan analisis kebutuhan sistem, maka peneliti akan membuat diagramkonteks helpdesk system, untuk mengetahui alur dari sistem yang dibuat. Adapungambar diagram konteks dapat dilihat pada Gambar 7 sebagai berikut :

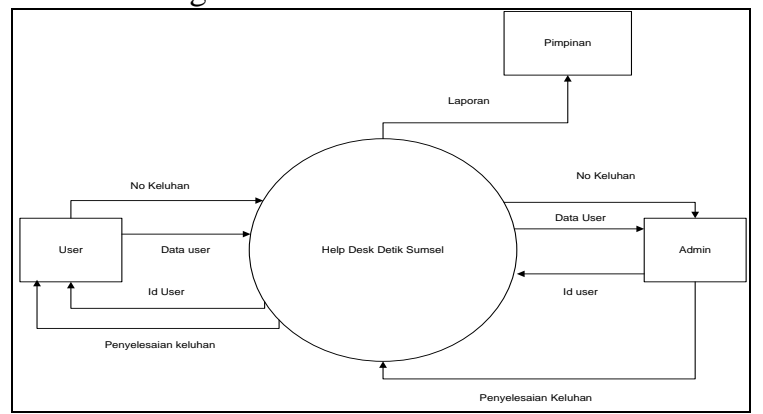

Gambar 6. Diagram Helpdesk System

\section{c. ERD}

ERD bertujuan melihat bagaimana hubungan antara table yang ada pada table-tabel yang saling berelasi, gambar relasi able dapat dilihat pada gambar 4.5.

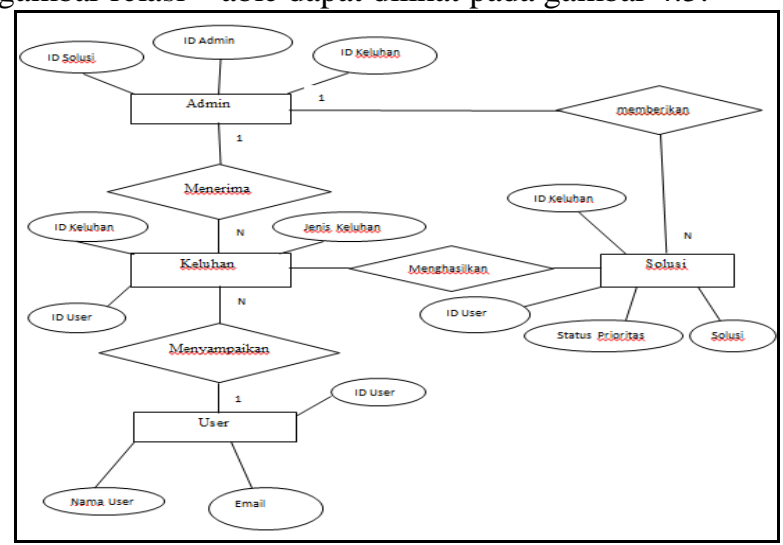

Gambar 7. ERD Pengusulan system

1) Investigasi dan Diagnosis

Setiap bagian staf service desk yang terlibat dan bertanggung jawab terhadap suatu penanganan insiden harus melakukan investigasi dan diagnosis yang menjadi sumber insiden. Saat melakukan investigasi setiap tindakan yang diambil harus dicatat dan dicantumkan dalam dokumentasi formulir insiden. ini bertujuan sebagai data rekaman tindakan penanganan suatu insiden yang d digunakan kemudian hari. Beberapa tindakan yang ada dalam investigasi adalah sebagai berikut:

a) Mengkonfirmasi dampak yang ditimbulkan oleh insiden.

b) Mengidentifikasi berbagai kegiatan yang menyebabkan terjadinya insiden.

c) Memahami kronologi terjadinya insiden.

Sehingga guna mempermudah dalam pelaksanaan investigasi dan diagnosis terhadap insiden yang terjadi akan dirancang sebuah pencarian fakta yang nantinya bisa menyajikan sebuah laporan yang akan mempermudah dalam investigasi terhadap insiden yang terjadi dan jika insiden terjadi berulang kali maka bisa dijadikan subuah problem yang terjadi pada sistem pelayanan tersebut dan harus segera ditangani. Dan berikut rangkaian yang digunakan dalam pencarian dan investigasi insiden pada detik sumsel.

d. Tabel incident

Tabel insiden digunakan untuk mendeklarasikan beberapa masalah yang sering laporkan oleh user, sehingga nanti able insiden ini akan digunakan sebagai acuan dalam menyelesaikan permaslahan yang ada

Tabel 5. Incident

\begin{tabular}{|c|l|c|}
\hline No & \multicolumn{1}{|c|}{ Incident } & Kode \\
\hline 1 & Iklan tidak sempurna tampil & K01 \\
\hline 2 & Waktu tampil yang iklan yang tidak bisa dipastikan & K02 \\
\hline 3 & Konfirmasi lambat karena sering terjadi pemesanan secara bersamaan & K03 \\
\hline 4 & Proses pembayaran yang rumit & K04 \\
\hline 5 & Jangka waktu berita terlalu lama & K05 \\
\hline 6 & Kesalahan berita & K06 \\
\hline 7 & Jaringan lambat & K07 \\
\hline
\end{tabular}

1) Tabel Penanganan Incident

Tabel penenganan keluhan akan digunakan sebagai pormula yang akan diberikan terhadap insiden yang telah terjadi, sehingga nanti dari tabel penanganan keluhan ini akan diperoleh sebuah solusi penanganan permasalahan.

Tabel 6. Penanganan incident

\begin{tabular}{|c|l|c|}
\hline No & \multicolumn{1}{|c|}{ Solusi } & Kode \\
\hline 1 & $\begin{array}{l}\text { Periksa iklan apakah sesuai pesanan, } \\
\text { karena setiap yang dipesan akan } \\
\text { disesuaikan dengan ukuran iklan }\end{array}$ & S01 \\
\hline 2 & $\begin{array}{l}\text { Pastikan pesanan sudah benar dan } \\
\text { koneksi jaringan dalam keadaan baik } \\
\text { serta muat ulang pada alamat detik } \\
\text { sumsel. }\end{array}$ & S02 \\
\hline 3 & $\begin{array}{l}\text { Pesanan iklan akan diproses dalam } \\
\text { waktu 12 jam dan selama proses } \\
\text { berlangsung silakan menunggu } \\
\text { konfirmasi dari penyedia layanan. }\end{array}$ & S03 \\
\hline 4 & $\begin{array}{l}\text { Silakan lakukan transfer dana setelah } \\
\text { mendapatkan kode iklan. }\end{array}$ & S04 \\
\hline 5 & $\begin{array}{l}\text { Lakukan pengiriman berita secara } \\
\text { estaped terhadap tim redaksi pusat, } \\
\text { sehingga hasil dari berita dapat direvisi } \\
\text { baik dalam bentuk tata bahasa dan } \\
\text { kebenaran berita, termasuk untuk } \\
\text { mengatasi minimnya jaringan terutama } \\
\text { yang bertugas didaerah. }\end{array}$ & S05 \\
\hline 6 & Hubungi CS & S06 \\
\hline
\end{tabular}

2) Tabel hubungan jenis keluhan dan keluhan

Tabel hubungan jenis keluhan dan keluhan ini akan mendeklarasikan beberakah keluhan yang terjadi dan termasuk kedalam jenis keluhan yang mana.

Tabel 7. Hubungan jenis keluhan dan keluhan

\begin{tabular}{|c|l|}
\hline No & \multicolumn{1}{|c|}{ Aturan } \\
\hline 1 & $\begin{array}{l}\text { IF L01 THEN K01 AND K02 AND K03 } \\
\text { AND K04 }\end{array}$ \\
\hline 2 & IF L02 THEN K05 AND K06 AND K07 \\
\hline
\end{tabular}


3) Tabel Hubungan Keluhan Dan Solusi

Tabel hubungan keluhan dan solusi merupakan sebuah basis pencarian fakta agar mendapatkan solusi dalam setiap keluhan yang terjadi.

Tabel 8. Hubungan Keluhan dan Solusi

\begin{tabular}{|c|c|}
\hline No & Aturan \\
\hline 1 & IF K01 THEN S01 AND S06 \\
\hline 2 & IF K02 THEN S02 AND S06 \\
\hline 3 & IF K03 THEN S03 AND S06 \\
\hline 4 & IF K04 THEN S04 AND S06 \\
\hline 5 & IF K05 THEN S05 AND S06 \\
\hline 6 & IF K06 THEN S05 AND S06 \\
\hline 7 & IF K07 THEN S05 AND S06 \\
\hline 8 & $\begin{array}{l}\text { IF K01 AND K02 THEN S01 AND S02 AND } \\
\text { S06 }\end{array}$ \\
\hline 9 & $\begin{array}{l}\text { IF K01 AND K03 THEN S01 AND S03 AND } \\
\text { S06 }\end{array}$ \\
\hline 10 & $\begin{array}{l}\text { IF K01 AND K04 THEN S01 AND S04 AND } \\
\text { S06 }\end{array}$ \\
\hline 11 & $\begin{array}{l}\text { IF K01 AND K05 THEN S01 AND S05 AND } \\
\text { S06 }\end{array}$ \\
\hline 12 & $\begin{array}{l}\text { IF K01 AND K06 THEN S01 AND S05 AND } \\
\text { S06 }\end{array}$ \\
\hline 13 & $\begin{array}{l}\text { IF K01 AND K07 THEN S01 AND S05 AND } \\
\text { S06 }\end{array}$ \\
\hline 14 & $\begin{array}{l}\text { IF K02 AND K03 THEN S02 AND S03 AND } \\
\text { S06 }\end{array}$ \\
\hline 15 & $\begin{array}{l}\text { IF K02 AND K04 THEN S02 AND S04 AND } \\
\text { S06 }\end{array}$ \\
\hline 16 & $\begin{array}{l}\text { IF K02 AND K05 THEN S02 AND S05 AND } \\
\text { S06 }\end{array}$ \\
\hline 17 & $\begin{array}{l}\text { IF K02 AND K06 THEN S02 AND S05 AND } \\
\text { S06 }\end{array}$ \\
\hline 18 & $\begin{array}{l}\text { IF K02 AND K07 THEN S02 AND S05 AND } \\
\text { S06 }\end{array}$ \\
\hline 19 & $\begin{array}{l}\text { IF K03 AND K04 THEN S03 AND S04 AND } \\
\text { S06 }\end{array}$ \\
\hline 20 & $\begin{array}{l}\text { IF K03 AND K05 THEN S03 AND S05 AND } \\
\text { S06 }\end{array}$ \\
\hline 21 & $\begin{array}{l}\text { IF K03 AND K06 THEN S03 AND S05 AND } \\
\text { S06 }\end{array}$ \\
\hline 22 & $\begin{array}{l}\text { IF K03 AND K07 THEN S03 AND S05 AND } \\
\text { S06 }\end{array}$ \\
\hline 23 & $\begin{array}{l}\text { IF K04 AND K05 THEN S04 AND S05 AND } \\
\text { S06 }\end{array}$ \\
\hline 24 & $\begin{array}{l}\text { IF K04 AND K06 THEN S04 AND S05 AND } \\
\text { S06 }\end{array}$ \\
\hline 25 & $\begin{array}{l}\text { IF K04 AND K07 THEN S04 AND S05 AND } \\
\text { S06 }\end{array}$ \\
\hline 26 & IF K05 AND K06 THEN S05 AND S06 \\
\hline 27 & IF K05 AND K07 THEN S05 AND S06 \\
\hline 28 & IF K06 AND K07 THEN S05 AND S06 \\
\hline 29 & $\begin{array}{l}\text { IF K01 AND K02 AND K03 THEN S01 AND } \\
\text { S02 AND S03 AND S06 }\end{array}$ \\
\hline 30 & $\begin{array}{l}\text { IF K01 AND K02 AND K04 THEN S01 AND } \\
\text { S02 AND S04 AND S06 }\end{array}$ \\
\hline 31 & $\begin{array}{l}\text { IF K01 AND K02 AND K05 THEN S01 AND } \\
\text { S02 AND S05 AND S06 }\end{array}$ \\
\hline
\end{tabular}

\begin{tabular}{|c|l|}
\hline 32 & $\begin{array}{l}\text { IF K01 AND K02 AND K06 THEN S01 AND } \\
\text { S02 AND S05 AND S06 }\end{array}$ \\
\hline 33 & $\begin{array}{l}\text { IF K01 AND K02 AND K07 THEN S01 AND } \\
\text { S02 AND S05 AND S06 }\end{array}$ \\
\hline 34 & $\begin{array}{l}\text { IF K01 AND K02 AND K03 AND K04 THEN } \\
\text { S01 AND S02 AND S03 AND S04 AND S06 }\end{array}$ \\
\hline 35 & $\begin{array}{l}\text { IF K01 AND K02 AND K03 AND K05 THEN } \\
\text { S01 AND S02 AND S03 AND S05 AND S06 }\end{array}$ \\
\hline 36 & $\begin{array}{l}\text { IF K01 AND K02 AND K03 AND K06 THEN } \\
\text { S01 AND S02 AND S03 AND S05 AND S06 }\end{array}$ \\
\hline 37 & $\begin{array}{l}\text { IF K01 AND K02 AND K03 AND K07 THEN } \\
\text { S01 AND S02 AND S03 AND S05 AND S06 }\end{array}$ \\
\hline
\end{tabular}

7. Penyelesaian dan Penanganan

Proses ini dilakukan untuk menetapkan tindakan penyelesaian insiden. Langkah penyelesaian dan penaganan dapat dilakukan oleh unit service desk sebagai pihak yang menemukan insiden dari user atau staf teknisi yang sedang melakukan kegiatan konfigurasi. Saat langkah yang ditetapkan telah dilakukan maka perlu dilakukan pengujian untuk memastikan penaganan sudah selesai dan pelayanan kembali normal. Tindakantindakan yang perlu dilakukan adalah sebagai berikut.

a. Meminta dan memandu pengguna melakukan tindakan yang diperlukan secara langsung.

b. Memberikan solusi terhadap insiden yang dialami oleh client.

Sehingga guna mendapatkan sebuah solusi maka akan dirancang sebuah tampilan interface sehingga mampu mempermudah dalam pelaksanaan penanganan insiden. Tanpilan interface dapat dilihat sebagai berikut:

8. Tampilan Menu koresponden user

Rancangan menu keluhan dapat dilihat pada rancangan gambar 8 berikut :

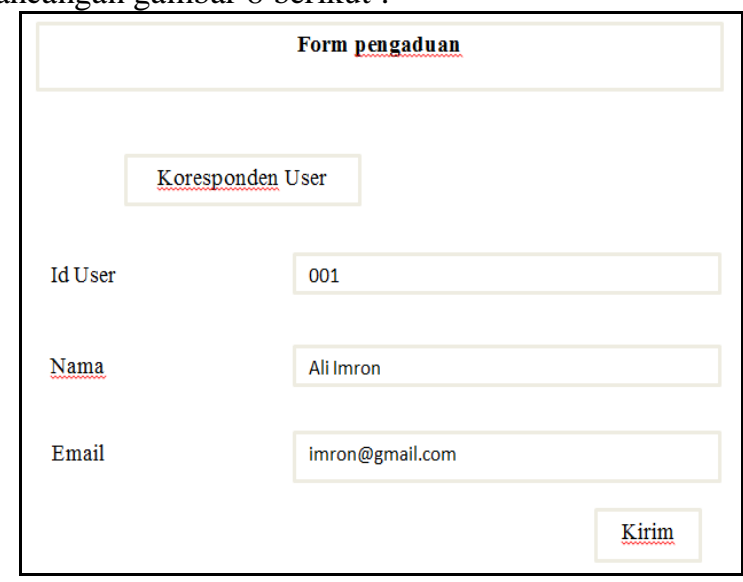

Gambar 8. Tampilan Menu Korenponden User

a. Halaman input Keluhan

Rancangan halaman pengaduan merupakan tampilan dimana incident yang dialami oleh user dapat dapat disampaikan dan menjadi pertimbangan oleh admin. Halaman input keluhan dapat dilihat pada rancangan gambar 9 berikut: 


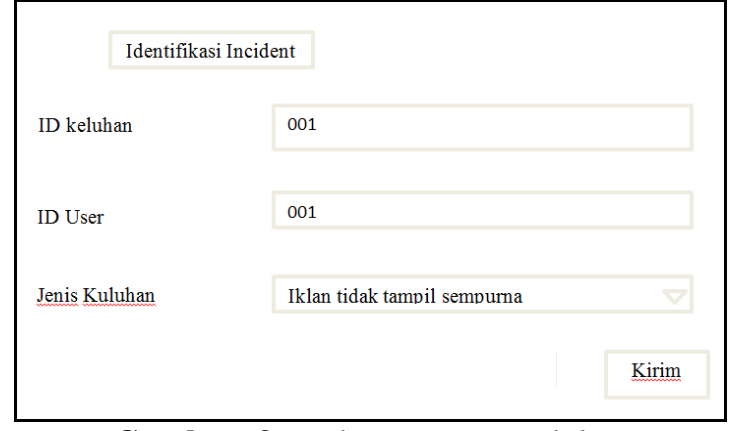

Gambar 9. Halaman input Keluhan

b. Tampilan Halaman solusi

Halaman hasil keluhan merupakan tampilan dimana user (pengguna) mendapatkan penanganan terhadap insiden yang dialaminya.

\begin{tabular}{|l|l|}
\hline \multicolumn{1}{|l|}{ Klarifikasi Penanganan incident } \\
\hline ID User & 001 \\
\hline Status Prioritas & Medium/ respon 1 hari/ resolves 12jam \\
\hline ID Keluhan & 001 \\
\hline Solusi & Periksa Iklan apakan sesuai Pesanan, hubungics \\
\hline
\end{tabular}

Gambar 10. Halaman Solusi

c. Halaman report

Halaman report digunakan oleh admin untuk mendapatkan laporan, sehingga admin akan melihat masalah apa saja yang paling sering dialami oleh user.

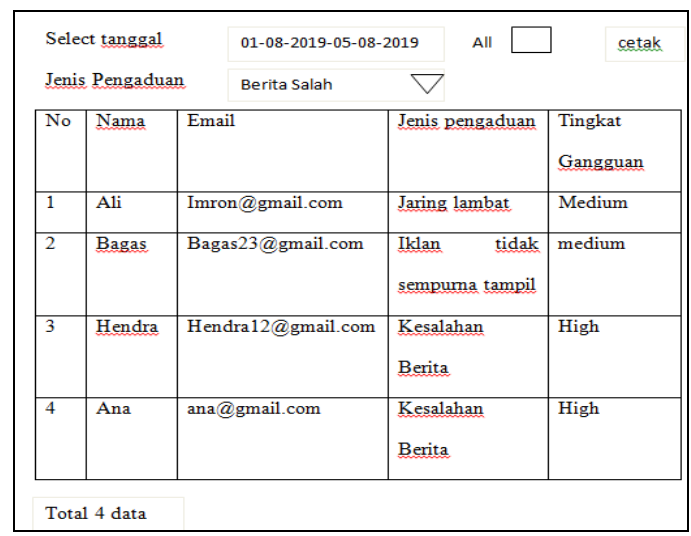

Gambar 11. Halaman report

\section{Kesimpulan}

Berdasarkan analisis dari hasil penelitian menggunakan informan yang mengacu pada framework ITIL dengan domain problem management dan incident management terhadap Detik Sumsel, maka dapat diambil kesimpulannya yaitu :

1. Analisis terhadap layanan yang terdapat pada detik sumsel meliputi layanan iklan dan layanan berita guna memberikan sebuah layanan yang baik terhadap user.
2. Incident yang diperoleh sesuai dengan data yang didapat dari IT support detik sumsel meliputi:

a. Iklan tidak sempurna tampil (K01)

b. Waktu tampil yang iklan yang tidak bisa dipastikan (K02)

c. Konfirmasi lambat karena sering terjadi pemesanan secara bersamaan (K03)

d. Proses pembayaran yang rumit (K04)

e. Jangka waktu berita terlalu lama (K05)

f. Kesalahan berita (K06)

g. Jaringan lambat (K07)

3. Analisis menghasilkan sebuah perancangan helpdesk yang bisa dijadikan sebuah rujukan dalam perbaikan sistem yang berjalan sekarang guna memberikan pelayanan terbaik terhadap user.

4. Mesin pencarian fakta menggunakan logika forward chaining yang akan menyajikan sebuah data sesuai dengan fakta-fakta yang ada pada detik sumsel.

5. Hasil yang diperoleh dengan mesin pencarian fakta yaitu berupa penanganan insiden yang diajukan oleh user sesuai dengan insiden yang dialami user.

\section{Daftar Pustaka}

ISACA. 2012. COBIT, www.isaca.org, diakses : 08 Januari 2019.

Surendro. 2009. Implementasi Tata Kelola TI. (7-8).

Edi Susanto. 2014. Capability Model Framewrok COBIT 5,11-15.

Wikipedia. 2013. Optimalisasi, www.wikipedia.org, diakses: : 08 Januari 2019.

Sugiyono. 2012. Statistika, 80.

Sugiyono. 2012. Statistika, 81.

Statistik, B. P., \& Selatan, P. S. 2019, Maret 16 Retrieved from https://sumsel.bps.go.id. 